\title{
Transcutaneous Bilirubin Assessment for Screening of Hyperbilirubinemia in Term- and Near-Term Neonates With Jaundice: A Comparative Study
}

\author{
Gholam Reza Kalvandi', Iraj Shahramian ${ }^{2 *}$, Mojtaba Delaramnasab ${ }^{3}$, Maryam Jozaei $^{4}$ \\ ${ }^{1}$ Assistant Professor, Department of Pediatrics, Imam Khomeini Hospital, Ilam University of Medical Sciences, Ilam, Iran \\ ${ }^{2}$ Associate Professor, Pediatric Ward, Amir-Al-Momenin Hospital, Zabol University of Medical Sciences, Zabol, Iran \\ ${ }^{3}$ Clinical Research Development Unit, Amir-Al-Momenin Hospital, Zabol University of Medical Sciences, Zabol, Iran \\ ${ }^{4}$ Student Research Committee, Ilam University of Medical Sciences, Ilam, Iran
}

\author{
*Correspondence to \\ Iraj Shahramian, Pediatric Ward, \\ Amir-Al-Momenin Hospital, Zabol \\ University of Medical Sciences, \\ Zabol, Iran. \\ Tel: +985432232166 \\ Email: ir_buper@yahoo.com
}

Received June 9, 2017

Accepted September 24, 2017

Published online September 31, 2017

as follows: Kalvandi

GR, Shahramian I,

Delaramnasab M, Jozaei

M. Transcutaneous

bilirubin assessment

for screening of

hyperbilirubinemia

in term- and near-

term neonates with

jaundice: a comparative

study. Int J Basic Sci

Med. 2017;2(3):147-

150. doi:10.15171/

ijbms.2017.27.

\begin{abstract}
Introduction: Hyperbilirubinemia is a common condition in neonates. In this study, we aimed to investigate the association of total serum bilirubin (TSB) with sternum transcutaneous bilirubin (TcB) level obtained by KJ-8000 Transcutaneous bilirubin meter (KEJIAN medical apparatus). Methods: Eighty newborns were enrolled in the present prospective cross-sectional study. At first, blood sampling was performed for determination of TSB, and immediately after that, TcB levels were recorded at the sternum skin by KJ-8000 device. Data was analyzed by statistical software SPSS version 21.0.

Results: The mean gestational age of the infants was $38.2 \pm 1.5$ weeks. The mean level of TSB was $13.52 \pm 4 \mathrm{mg} / \mathrm{dL}$, while the mean value of TcB was $13.71 \pm 3.53 \mathrm{mg} / \mathrm{dL}$. Pearson correlation analysis showed a correlation coefficient of $r=0.770$ between sternum TcB recorded by KJ-8000 device and TSB.

Conclusion: Given a strong correlation between TCB and TSB levels, it is advised the transcutaneous bilirubinometery be considered as the screening method in infant jaundice. Keywords: Hyperbilirubinemia, Total serum bilirubin, Transcutaneous bilirubin, Neonates
\end{abstract}

\section{Introduction}

Hyperbilirubinemia is a common and often benign disorder in neonates, as few cases would require medical intervention. In the first week of life, about $60 \%$ of term and $80 \%$ of preterm infants develop jaundice. ${ }^{1}$ Although bilirubin may promote a physiologic antioxidant role, elevated levels of indirect (non-conjugated) bilirubin can be potentially neurotoxic. Although direct (conjugated) bilirubin represent the minimum threat for the neurological system, direct hyperbilirubinemia may proclaim either a serious hepatic condition or a systemic disease and lead to permanent brain damage.

Screening for hyperbilirubinemia, either by measuring total serum bilirubin (TSB) or transcutaneous bilirubin $(\mathrm{TcB})$ is a perquisite in jaundiced newborns. ${ }^{2}$ Regardless of hyperbilirubinemia etiology, early diagnosis and treatment of this phenomenon is vital in preventing kernicterus and cerebral damage caused by bilirubin deposition. Evaluation of neonatal jaundice by visual examination of neonate's skin is a familiar routine in infants. Nonetheless, this method can be erroneous especially for unexperienced clinicians due to the effect of both natural neonates' skin color and hemoglobin level. Blood sampling from the heel for determining TSB is the gold standard method in neonates. ${ }^{3}$ However, needle stick causes pain and anxiety, and may lead to long-term complications such as infections (i.e. osteomyelitis) and/or scar in the site of puncture. Furthermore, incessant blood samplings can be associated with iatrogenic anemia, especially in pre-term infants. ${ }^{4}$ Determination of bilirubin through

Copyright (C) 2017 The Author(s); Published by Zabol University of Medical Sciences. This is an open-access article distributed under the terms of the Creative Commons Attribution License (http://creativecommons.org/licenses/by/4.0), which permits unrestricted use, distribution, and reproduction in any medium, provided the original work is properly cited. 
skin (i.e. TcB) is a proposed substitute for screening hyperbilirubinemia in term and near-term infants. ${ }^{5,6}$ This method has the advantage of less need for blood sampling in newborns and therefore the least risk for trauma and infection in neonates. Recent studies have shown that using $\mathrm{TcB}$ reduced the need for blood sampling by $34 \%-38 \%$ in neonates with hyperbilirubinemia., ${ }^{70}$ In addition, the procedure is time-saving because there is no need to wait for the results of routine laboratory tests. ${ }^{6}$ Furthermore, using $\mathrm{TcB}$ strategy is financially more affordable in long-term; thereby rendering this method a suitable approach for large facilities. ${ }^{9}$ And finally, the method is a non-invasive and pain-free procedure which makes it more attractive in clinical practice.

Regarding aforementioned statements, the assessment of accuracy and precision of TcB determination using medical devices is essential. Nevertheless, the current automated devices for this purpose are expensive and not affordable in low-income care-centers. There have been some reports on the correlation of TSB and TcB determined by multiple instruments such as Dräger Jaundice Meter (JM) models, and Bilichek meter. ${ }^{1,10}$ These aside, the majority of studies on the correlation of TSB and TcB are retrospective leading to inconclusive results. ${ }^{11-13}$ In the present study, we aimed to determine both the accuracy and reliability of KJ-8000 transcutaneous bilirubin meter (KEJIAN medical apparatus) in cutaneous bilirubin measurement in neonates, and to compare its measures with those of TSB.

\section{Methods}

The population under study comprised neonates delivered above 35 weeks of gestation affected by jaundice. The study was done during January 2012-December 2012 in Imam Khomeini hospital of Ilam city in west of Iran.

The sample size was determined as $\mathrm{n}=80$ considering type I error of 5\%, strength of $90 \%$ and correlation coefficient (r) of 0.83 . The patients were selected from those who were first-time visitors to the hospital diagnosed with jaundice. Demographical data (delivery age, neonates' sex, mother's age, birth weight, weight at visiting) were obtained by a questionnaire.

Exclusion criteria included (1) neonates with previous phototherapy, (2) those with previous blood exchange, (3) neonates with congenital disorders, (4) those who were diagnosed with sepsis or peripheral perfusion disorder, and (5) pre-term infants of $<35$ weeks delivery age.

At first, venous samples were drawn from the heel for the determination of TSB. Then, TcB level was determined using KJ-8000 transcutaneous bilirubin meter (KEJIAN medical apparatus) instrument at the skin of neonates' sternum. The TcB level was determined as a mean of three times performance.

Statistical analysis was done using SPSS software (version 21.0). Normal distribution of data was checked by Shapiro-Wilk test. Statistical tests were Pearson correlation coefficient, and independent samples $t$ test for determination of any significant association between TSB and TcB, and any significant difference in TcB regarding different groups of patients, respectively. Simple regression model was used to determine if TSB level could be estimated by TcB.

\section{Results}

In the present study, 80 neonates were recruited. The mean of gestational age was $38.2 \pm 1.5$ weeks, and the mean age of neonates was $6.8 \pm 5$ days (Table 1). The values obtained for TSB and TcB have been demonstrated in Table 2.

Significant associations were found between TSB and TcB levels $(r=0.770, P<0.0001)$, as well as a significant difference between TSB and TcB with TcB value obtained by KJ-8000 device ( $r=0.519, P<0.0001)$ (see Figure 1 and Table 3 for details).

Linear regression model rendered the following relationship between TSB and TcB levels (Table 4):

$\mathrm{TSB}_{\mathrm{mg} / \mathrm{dL}}=-1.31+\left(0.981 \times \mathrm{TcB}_{\mathrm{mg} / \mathrm{dL}}\right)$.

\section{Discussion}

$\mathrm{TcB}$ has been suggested by the American Academy of Pediatrics (AAP) as a replacement for routine TSB measurements. Depending on the device and target populations, TcB may either overestimate or underestimate bilirubin level in jaundiced neonates. ${ }^{12,14,15} \mathrm{TcB}$ screening in early hours of life may be a useful marker to foretell the possibility of hyperbilirubinemia in later days of life. ${ }^{12,16-19}$ In the present study, we showed that TSB and sternum $\mathrm{TcB}$ levels were plausibly correlated with each other in full term and near term infants with hyperbilirubinemia. The correlation obtained between these 2 methods was $r=0.770$ in our experiment. The correlation of TcB with

Table 1. Basic Characteristics of 80 Neonates With Jaundice

\begin{tabular}{lcc}
\hline Variables & Mean & SD \\
\hline Gestational age (wk) & 38.24 & 1.5 \\
Neonate's birth weight $(\mathrm{g})$ & 3134.32 & 506.95 \\
Neonate's weight at visiting (g) & 3032.84 & 528.72 \\
Neonate's age at visiting (d) & 6.89 & 5 \\
\hline
\end{tabular}

Abbreviation: SD, standard deviation.

Table 2. Total Serum Bilirubin and Transcutaneous Bilirubin Levels Measured in 80 Jaundiced Neonates

\begin{tabular}{lll}
\hline Variables & $\begin{array}{l}\text { Mean } \\
(\mathbf{n = 8 0})\end{array}$ & SD \\
\hline TSB $(\mathrm{mg} / \mathrm{dL})$ & 13.52 & 4.09 \\
TCB $(\mathrm{mg} / \mathrm{dL}, \mathrm{KJ}-8000$ instrument) & 13.71 & 3.53 \\
$\begin{array}{l}\text { Difference between TSB and cutaneous } \\
\text { bilirubin of KJ-8000 }\end{array}$ & -0.185 & 2.64 \\
\hline
\end{tabular}

Abbreviation: SD, standard deviation; TCB, transcutaneous bilirubin; TSB, total serum bilirubin. 
Table 3. Correlation Coefficients Between Bilirubin Levels Assessed by Laboratory Biochemical Method (Total Serum Bilirubin) and KJ-8000Measured Transcutaneous Bilirubin

\begin{tabular}{|c|c|c|c|c|}
\hline Variable & & TSB (mg/dL) & TcB (KJ-8000 instrument) & Difference Between TSB and TcB of KJ-8000 \\
\hline \multirow{2}{*}{$\mathrm{TSB}(\mathrm{mg} / \mathrm{dL})$} & $r$ & 1 & 0.770 & 0.519 \\
\hline & $P$ & NA & $<0.0001$ & $<0.0001$ \\
\hline \multirow{2}{*}{$\begin{array}{l}\text { TcB (mg/dL, KJ-8000 } \\
\text { instrument) }\end{array}$} & $r$ & NA & 1 & -0.140 \\
\hline & $P$ & NA & NA & 0.1 \\
\hline
\end{tabular}

Abbreviations: NA, not applicable; TcB, transcutaneous bilirubin; TSB, total serum bilirubin.

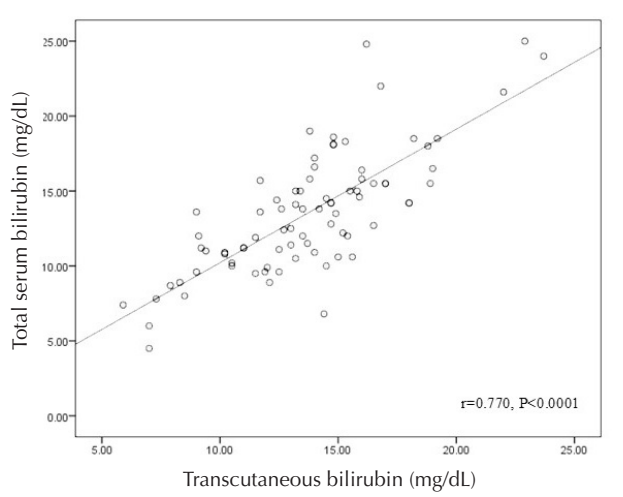

Figure 1. Pearson Correlation Coefficient Between Transcutaneous Bilirubin Recorded by KJ-8000 Bilirubinometer at the Sternum of Infants and Total Serum Bilirubin in Jaundiced Neonates.

Table 4. Regression Model Between Total Serum Bilirubin and KJ8000-Measured Transcutaneous Bilirubin

\begin{tabular}{llccc}
\hline Variable & $\begin{array}{l}\text { Regression Line } \\
\text { Coefficient }(\boldsymbol{\beta})\end{array}$ & $\boldsymbol{\theta}$ & $\boldsymbol{P}$ & $\boldsymbol{t}$ \\
\hline TSB & 0.891 & 0.770 & $<0.0001$ & 10.72 \\
Constant & 1.31 & - & 0.269 & 1.114 \\
\hline
\end{tabular}

Abbreviation: TSB, total serum bilirubin.

TSB using different medical instruments has been reported in the range of 0.550 to 0.918 in previous reports. ${ }^{3,20-23} \mathrm{We}$ believe that the difference between these coefficient values may be because of variable sensitivities of instruments recruited in these studies. In addition, some other factors may impart in this area such as the location of $\mathrm{TcB}$ record. The highest correlation between TcB and TSB was noted for forehead and sternum areas, ${ }^{1,5}$ however, the sternum results were more accurate compared to forehead results. ${ }^{1}$ Nevertheless, the values of $\mathrm{TcB}$ derived from forehead or sternum did not significantly differ in another study. ${ }^{6}$ In the study of Badiee et al in Isfahan province of Iran, total serum and cutaneous (forehead and sternum) bilirubin were measured in 72 infants. In this study, correlation coefficient between TSB and cutaneous bilirubin recorded in sternum $(r=0.55, P=0.05)$ was lower than the coefficient observed in the present study $(r=0.77)$. However, the correlation coefficient was obtained between TSB and cutaneous bilirubin in forehead $(r=0.83, P=0.05) .{ }^{23}$ Here, we used sternum to measure TcB which is used in majority of studies. The correlation index between TcB and TSB may also be affected by gestational age, ${ }^{20}$ and age of neonates. ${ }^{20}$ The correlation between TcB and TSB was reported to be lower (0.82) in infants older than 72 hours in comparison with the correlation (0.96) in younger ( $<72$ hours) newborns. ${ }^{20}$ In spite of this, El-Kabbany et al described a better correlation index between TcB and TSB in newborns older than 63 days. ${ }^{1}$

In the present study, positive correlation was observed between TSB and TcB levels and a significant difference of means between TSB and TcB was measured by KJ$8000(r=0.519, P<0.0001)$. This result indicates that the difference between TSB and TcB estimated by KJ-8000 assay increases with elevation of TSB. In the study of Jones et al in the United States, correlation of TSB with sternum and forehead TcB was evaluated by JM-105 device. ${ }^{2}$ Similar to our observation, the correlation of TSB and TcB was found to be less precise with increasing TSB level, as the correlation coefficient was reduced from $r=0.82$ at TSB $>10 \mathrm{mg} / \mathrm{dL}$ to $r=0.52$ at TSB $>15 \mathrm{mg} / \mathrm{dL} .{ }^{2}$ Accordingly, it is more appropriate to use TSB in elevated levels of bilirubin for deciding on strategic management (phototherapy or blood exchange).

We detected a regression model for predicting TSB levels based on $\mathrm{TcB}$ as "TSB $\mathrm{mg} / \mathrm{dL}=-1.31+(0.981 \times$ $\mathrm{TcB} \mathrm{mg} / \mathrm{dL})$ ". In a study by Rubaltelli et al, 210 neonates in 6 different European hospitals were evaluated by TcB. For comparison, they used bilirubin level determined by HPLC-B method. ${ }^{6}$ In the study of Tayaba et al, TSB level was measured for both term and pre-term neonates, and cutaneous bilirubin was also assessed by Colormate III instrument. They found a linear relationship between serum and cutaneous bilirubin with linear regression model of "TSB $=-0.504+(0.986 \times \mathrm{TcB}) .{ }^{24}$ In the study of Badiee et al, linear regression model of "TSB $=2.18+(0.68$ $\times$ forehead $\mathrm{TcB})$ " was obtained. ${ }^{23}$ The high regression coefficient of 0.981 indicates that TSB can be anticipated by $\mathrm{TcB}$ level recorded by KJ-8000 instrument, with excellent accuracy.

\section{Conclusion}

In our study, the association of TSB with TcB measured by KJ-8000 instrument was acceptable (high regression coefficient, $\beta=0.98$ ). This highlights the usefulness of TcB method of bilirubin determination as a reliable substitute 
for screening jaundiced neonates.

\section{Ethical Approval}

Our study was performed according to the ethical standards reported by the COPE (Committee on Publication Ethics) available at https://publicationethics. org. Informed consent was obtained from mothers' of the neonates before their inclusion in the research.

\section{Competing Interests}

Authors declare no competing interests.

\section{References}

1. El-Kabbany ZA, Toaima NN, Shedid AM. Implementation and validating transcutaneous bilirubinometry for neonates. Egyptian Pediatric Association Gazette. 2017;65(2):38-42. doi: 10.1016/j.epag.2017.01.003.

2. Jones DF, McRea AR, Knowles JD, et al. A prospective comparison of transcutaneous and serum bilirubin within brief time intervals. Clin Pediatr (Phila). 2017;56(11):10131017. doi:10.1177/0009922817701170.

3. Kurnianto A, Bermawi H, Ramadanti A, Bahar E. Transcutaneous bilirubinometry to estimate total serum bilirubin in neonatal jaundice. Paediatr Indones. 2017;57(1):8-11. doi:10.14238/pi57.1.2017.8-11.

4. Lilien LD, Harris VJ, Ramamurthy RS, Pildes RS. Neonatal osteomyelitis of the calcaneus: complication of heel puncture. J Pediatr. 1976;88(3):478-480.

5. Moey KS. Transcutaneous bilirubin measurement to estimateserumbilirubinin neonatesinamulti-ethniccohort: a literature review. Proceedings of Singapore Healthcare. 2017;26(1):42-57. doi:10.1177/2010105816665854.

6. Rubaltelli FF, Gourley GR, Loskamp N, et al. Transcutaneous bilirubin measurement: a multicenter evaluation of a new device. Pediatrics. 2001;107(6):1264-1271.

7. Mishra S, Chawla D, Agarwal R, Deorari AK, Paul VK, Bhutani VK. Transcutaneous bilirubinometry reduces the need for blood sampling in neonates with visible jaundice. Acta Paediatr. 2009;98(12):1916-1919. doi:10.1111/j.16512227.2009.01505.x.

8. van den Esker-Jonker B, den Boer L, Pepping RM, Bekhof J. Transcutaneous Bilirubinometry in Jaundiced Neonates: A Randomized Controlled Trial. Pediatrics. 2016;138(6). doi:10.1542/peds.2016-2414.

9. Maisels MJ, Kring E. Transcutaneous bilirubinometry decreases the need for serum bilirubin measurements and saves money. Pediatrics. 1997;99(4):599-601.

10. Greco C, Iskander IF, Akmal DM, et al. Comparison between Bilistick System and transcutaneous bilirubin in assessing total bilirubin serum concentration in jaundiced newborns. J Perinatol. 2017;37(9):1028-1031. doi:10.1038/ jp.2017.94.

11. Katayama Y, Enomoto M, Kikuchi S, et al. Transcutaneous bilirubin measurement during phototherapy in term neonates. Pediatr Int. 2017;59(6):686-690. doi:10.1111/ ped.13248.

12. Olusanya BO, Mabogunje CA, Imosemi DO, Emokpae AA. Transcutaneous bilirubin nomograms in African neonates. PLoS One. 2017;12(2):e0172058. doi:10.1371/journal. pone.0172058.

13. Murli L, Thukral A, Sankar MJ, et al. Reliability of transcutaneous bilirubinometry from shielded skin in neonates receiving phototherapy: a prospective cohort study. J Perinatol. 2017;37(2):182-187. doi:10.1038/ jp.2016.189.

14. Ebbesen F, Vandborg PK, Trydal T. Comparison of the transcutaneousbilirubinometers BiliCheckand MinoltaJM103 in preterm neonates. Acta Paediatr. 2012;101(11):11281133. doi:10.1111/j.1651-2227.2012.02797.x.

15. Olusanya BO, Imosemi DO, Emokpae AA. Differences between transcutaneous and serum bilirubin measurements in Black African neonates. Pediatrics. 2016;138(3). doi:10.1542/peds.2016-0907.

16. Jain M, Bang A, Tiwari A, Jain S. Prediction of significant hyperbilirubinemia in term neonates by early non-invasive bilirubin measurement. World J Pediatr. 2017;13(3):222227. doi:10.1007/s12519-016-0067-1.

17. Fine KL, Carey WA, Schuster JAW, Bryant SC, Cook WJ, Karon BS. Defining the limitations of transcutaneous bilirubin measurement in late preterm newborns. J Perinatol. 2017;37(6):658-661. doi:10.1038/jp.2017.8.

18. Sarici SU, Gunes O, Koklu E, Serdar MA. Transcutaneous Bilirubin Levels during the First Month of Life in Term and Late-preterm Newborns. J Trop Pediatr. 2017;63(1):4-9. doi:10.1093/tropej/fmw008.

19. Kurhade KA, Purandare S. Twenty-four hours' transcutaneous bilirubin as a predictor of subsequent 3(rd) day neonatal hyperbilirubinemia. J Clin Neonatol. 2017;6(1):6-9. doi:10.4103/2249-4847.199752.

20. Pendse A, Jasani B, Nanavati R, Kabra N. Comparison of Transcutaneous Bilirubin Measurement With Total Serum Bilirubin Levels in Preterm Neonates Receiving Phototherapy. Indian Pediatr. 2017;54(8):641-643.

21. Shihadeh MD, Kheyami D, Al Jufairi M, Jaradat AA, Al Ansari EM. Transcutaneous Bilirubin Measurement Correlation with Total Serum Bilirubin in Healthy Newborns. Bahrain Medical Bulletin. 2016;38(4):208-210.

22. Mansouri M, Mahmoodnejad A, Taghizadeh Sarvestani R, Gharibi F. A Comparison between Transcutaneous Bilirubin $(\mathrm{TcB})$ and Total Serum Bilirubin (TSB) Measurements in Term Neonates. Int J Pediatr. 2015;3(3-1):633-641.

23. Badiee Z, Ghassami M, Adelnia M. Transcutaneous Bilirubinometry During Phototherapy in Preterm Infants. Journal of Isfahan Medical School. 2010;28(105):1-8.

24. Tayaba R, Gribetz D, Gribetz I, Holzman IR. Noninvasive estimation of serum bilirubin. Pediatrics. 1998;102(3):E28. 